\title{
Giant Undifferentiated Oropharyngeal Sarcoma: A Case Report and Review of the Literature
}

\author{
Ilson Sepúlveda ${ }^{a, e} \quad$ Michael Frelinghuysen ${ }^{b}$ Cesar García ${ }^{b}$ \\ Enrique Platin ${ }^{f} \quad$ M. Loreto Spencer ${ }^{c} \quad$ Pablo Ortega $^{a} \quad$ David Ulloa $^{d}$ \\ ${ }^{a}$ ENT-Head and Neck Surgery Service, ${ }^{b}$ Oncology Service, and ${ }^{c}$ Pathology Department, \\ General Hospital of Concepción, and ${ }^{\mathrm{d}}$ Private Practice, Concepción, and ${ }^{\mathrm{e}}$ Finis Terrae \\ University, School of Dentistry, Santiago, Chile; ${ }^{\mathrm{f}}$ Department of Oral and Maxillofacial \\ Radiology, University of North Carolina School of Dentistry, Chapel Hill, N.C., USA
}

\section{Key Words}

Computed tomography · Magnetic resonance imaging · Oropharynx $\cdot$ Sarcoma .

Chemoradiation therapy

\begin{abstract}
We report on a patient who presented to the Ear, Nose and Throat (ENT) clinic with swelling of the neck, dysphagia, headache, dyspnea and stridor. Imaging studies revealed an expansive heterogeneous process to the left retropharyngeal region. The mass was ovoid in shape, displaying moderate enhancement after intravenous contrast administration. Subsequently, a biopsy revealed the presence of undifferentiated sarcoma. The patient was treated with chemotherapy followed by radiation therapy, but follow-up exams at 6 months posttreatment revealed that while the tumor was stable, it persisted. Consequently, the patient was enrolled in a palliative care and pain control program and is currently being followed.

(C) 2014 S. Karger AG, Basel
\end{abstract}

\section{Introduction}

Sarcomas are very rare among head and neck neoplasms and represent only $1 \%$ of all primary tumors. They occur in a wide range of age groups but most often in children, adolescents, and young adults. Several environmental exposures have been proposed as causative agents in the development of sarcomas. Computed tomography (CT) and magnetic 
Sepúlveda et al.: Giant Undifferentiated Oropharyngeal Sarcoma: A Case Report and Review of the Literature

resonance imaging (MRI) are essential for preoperative staging and surgical planning. The management of soft tissue sarcomas in the head and neck is primarily surgical.

\section{Case Report}

We report on a 30-year-old female patient who presented to the Ear, Nose and Throat (ENT) clinic complaining of neck swelling, progressive dysphagia of 7 months duration, headaches, dyspnea primarily during the evening and stridor. The patient had a history of allergic rhinitis. A clinical exam revealed a swelling process in the oropharyngeal region behind the left anterior pillar distorting the palatal area and producing a significant elongation of the isthmus. A CT was performed revealing a large expansive cervical process on the left retropharyngeal region. It was ovoid in shape, heterogeneous and displaying moderate enhancement following intravenous contrast injection (fig. 1, fig. 2). The medial border of the mass crossed the middle line into the right side involving the left carotid space and pterigoid muscles (fig. 3). It reached the base of the skull and the left arch of C1. Due to its size, existent ipsilateral lymphadenopathies with hypodense centers in the II, III and IV ganglionar levels as large as $20 \mathrm{~mm}$ were present.

In addition, MRI was performed, showing an expansive process partially delimited and possibly encapsulated (fig. 4, fig. 5) with heterogeneous enhancement following intravenous contrast administration (fig. 6). The presence of some weak signals was suggestive of vascular structures within the mass (fig. 7). The mass measured approximately $4.8 \times 2.6 \times$ $4.1 \mathrm{~cm}$ in size with a weak left paravertebral enhancement around the ipsilateral vertebral artery at the C1 level. A biopsy revealed an undifferentiated sarcoma (fig. 8, fig. 9). Due to respiratory difficulty, a tracheostomy was performed.

The case was presented to the Head and Neck Tumor Board, where it was staged as an T3N2BM0 oropharyngeal tumor. Since the tumor was inoperable, chemotherapy followed by radiation therapy was recommended as the treatment of choice (fig. 10). After 6 months of treatment, the tumor was stable but persisted without evidence of progression. Consequently, the patient was enrolled in a pain management and palliative care program. The patient is currently being followed.

\section{Discussion}

In adults, the majority of soft tissue sarcomas (59\%) originate in the extremities, $19 \%$ in the trunk, $15 \%$ in the retroperitoneum and $9 \%$ in the head and neck [1]. Sarcomas of the head and neck occur in a wide range of age groups but most often in children, adolescents, and young adults. In children, as many as 35\% of rhabdomyosarcomas arise in the head and neck [2]. Sarcomas are very rare among head and neck neoplasms, representing only $1 \%$ of all primary tumors [3]. The vast majority of head and neck sarcomas arise sporadically in patients without identifiable predisposing genetic risk factors. Exposure to known environmental carcinogens can be identified in $<10 \%$ of the patients [4]. The paranasal sinuses and neck are the most frequent sites of origin of head and neck sarcomas.

Several environmental exposures have been proposed as causative agents in the development of sarcomas. Radiation to the head and neck area are known as contributing factors. The mean period of latency between irradiation and diagnosis of a radiation-induced sarcoma is $11.5-13$ years. The true calculated risk of developing a sarcoma after radiation treatments remains elusive due to the relative rarity of these tumors [5]. 
Sepúlveda et al.: Giant Undifferentiated Oropharyngeal Sarcoma: A Case Report and Review of the Literature

Sarcomas are malignancies that arise from transformed cells of mesenchymal origin. Current classification schemes attempt to group sarcomas into subtypes that are useful for determining prognosis and formulating treatment strategies. The vast majority of tumors, approximately $80 \%$ are of soft tissue origin, while the remaining $20 \%$ are of bony or cartilaginous origin [1]. The histologic grade is a consistent predictor of prognosis and its importance is illustrated in the American Join Committee on Cancer (AJCC) staging system for sarcomas [2].

Makimoto et al. [5] found that only $6(0.14 \%)$ out of 4,184 patients with soft tissue and osseous sarcoma of the head and neck had a history of radiation to the head and neck area. Malignant fibrous histiocytoma is probably the most frequent type of radiation-induced soft tissue sarcoma of the head and neck [6].

Imaging studies complement the physical examination in order to more accurately assess the size and location of the tumor. Since sarcomas are frequently associated with soft tissue invasion and bone destruction, CT and MRI are essential for preoperative staging and surgical planning in patients with these tumors [7].

The general protocols for the management of sarcomas are not universally applicable to the head and neck region. The delicate anatomy of the head and neck limits the ability to obtain wide surgical margins. This may be the reason for higher local recurrence rates and worse disease-specific survival of head and neck sarcomas compared to sarcomas arising at other sites [8]. The management of soft tissue sarcomas in the head and neck is primarily surgical. The type of surgical resection is determined by several factors, which include tumor location, tumor size, depth of invasion, involvement of adjacent structures, need for reconstruction and the patient's health status. The resection may include skin, subcutaneous tissue, and soft tissue or bone adjacent to the tumor. Residual disease is a powerful predictor of local recurrence and disease-related mortality [1,3].

Adjuvant radiation therapy is recommended after excision of high-grade and large sarcomas, positive surgical margins and regional lymph node dissection for nodal metastases. Postoperative radiotherapy improves local control rate $[9,10]$. However, local control by using adjuvant radiation therapy has not improved survival rate because patients often succumb to distant metastases. If the sarcoma is likely to be marginally resectable, preoperative radiotherapy can be considered. An advantage of preoperative radiotherapy is that the risk of late complications may be reduced because lower dose and smaller radiation fields are required [11].

When radiation therapy is delivered early in the course of a multidisciplinary approach, it could improve planning and ensure that treatment is delivered without delays imposed by postoperative complications [12].

Preoperative chemoradiation strategies have been investigated in the treatment of extremity and retroperitoneal soft tissue sarcomas over the past two decades but similar approaches for head and neck tumors have been investigated less. Such strategies are based primarily on maximizing local control while preserving function, and secondarily treating the potential of micrometastatic disease. The emphasis is on preventing recurrence and overall survival rate in selected patients [3].

\section{Conclusion}

Sarcomas are a rare entity arising from cells of mesenchymal origin. Imaging studies play an important role in the treatment planning. These exams provide valuable information about the growing pattern and involvement of critical anatomic organs. The general 
Sepúlveda et al.: Giant Undifferentiated Oropharyngeal Sarcoma: A Case Report and Review of the Literature

protocols for the management of sarcomas are not universally applicable to the head and neck region. The treatment of choice is surgical resection, combined with preoperative chemoradiation therapy in some cases.

\section{Disclosure Statement}

The authors have no conflicts of interest to disclose.

\section{References}

1 Sturgis EM, Potter BO: Sarcomas of the head and neck region. Curr Opin Oncol 2003;15:239-252.

-2 Van Damme JP, Schmitz S, Machiels JP, et al: Prognostic factors and assessment of staging systems for head and neck soft tissue sarcomas in adults. Eur J Surg Oncol 2010;36:684-690.

-3 Shellenberger TD, Sturgis EM: Sarcomas of the head and neck region. Curr Oncol Rep 2009;11:135-142.

4 McClay EF: Epidemiology of bone and soft tissue sarcomas. Semin Oncol 1989;16:264-272.

5 Makimoto Y, Yamamoto S, Takano H, et al: Imaging findings of radiation induced sarcoma of the head and neck. Br J Radiol 2007;80:790-797.

-6 Franco Gutiérrez VF, Llorente Pendás JL, Coca Pelaz A, Cabanillas Farpón R, Suárez Nieto C: Radiationinduced sarcomas of the head and neck. J Craniofac Surg 2008;19:1287-1291.

-7 de Bree R, van der Waal I, de Bree E, Leemans CR: Management of adult soft tissue sarcomas of the head and neck. Oral Oncology 2010;46:786-790.

8 Zagers GK, Ballo MT, Pisters PWT, et al: Prognostic factors for patients with localized soft-tissue sarcoma treated with conservation surgery and radiation therapy. Cancer 2003;97:2530-2543.

-9 Fayda M, Aksu G, Yaman Agaoglu F, et al: The role of surgery and radiotherapy in treatment of soft tissue sarcomas of the head and neck region: review of 30 cases. J Craniomaxillofac Surg 2009;37:42-48.

10 Colville RJ, Charlton F, Kelly CG, Nicoll JJ, McLean NR: Multidisciplinary management of head and neck sarcomas. Head Neck 2005;27:814-824.

11 Clark MA, Fisher C, Judson I, et al: Soft-tissue sarcomas in adults. N Engl J Med 2005;353:701-711.

12 O'Sullivan B, Gullane P, Irish J, et al: Preoperative radiotherapy for adult head and neck soft tissue sarcoma: assessment of wound complication rates and cancer outcome in a prospective series. World J Surg 2003;27:875-883. 


\section{Case Reports in Oncology}

\begin{tabular}{l|l}
\hline Case Rep Oncol 2014;7:718-726 & \\
\hline DOI: $10.1159 / 000368849$ & $\begin{array}{l}\text { ○ 2014 S. Karger AG, Basel } \\
\text { www.karger.com/cro }\end{array}$ \\
\hline
\end{tabular}

Sepúlveda et al:: Giant Undifferentiated Oropharyngeal Sarcoma: A Case Report and Review of the Literature

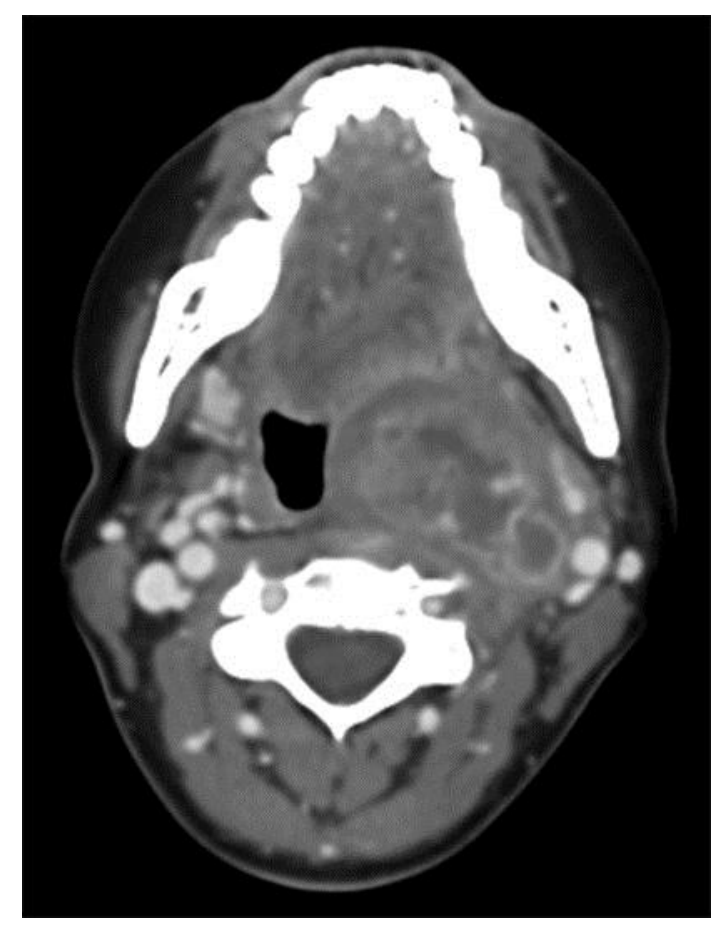

Fig. 1. Axial CT after intravenous contrast injection: heterogeneous expansive process on the left retropharyngeal region involving the ipsilateral carotid space.

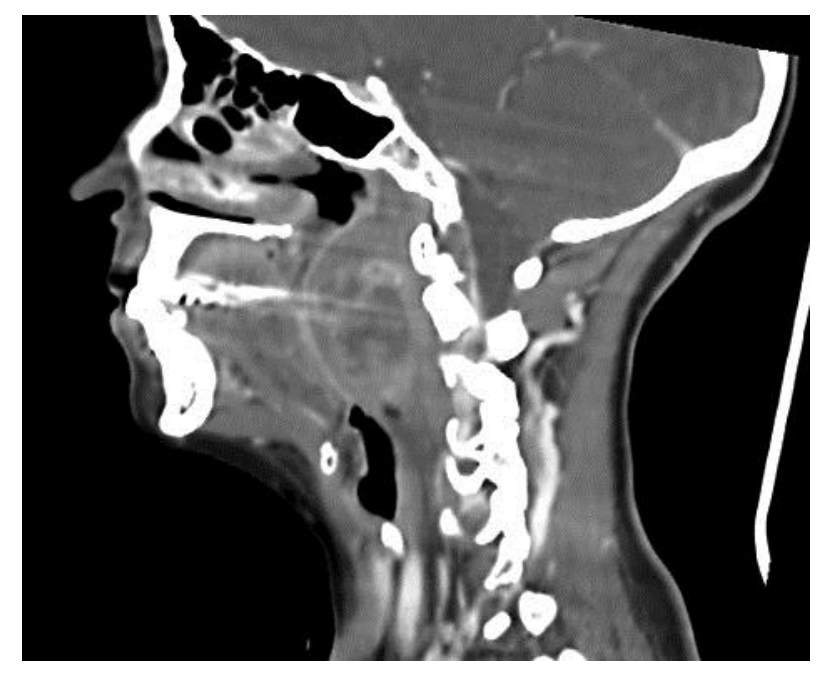

Fig. 2. Sagittal CT after intravenous contrast injection: expansive process compressing the base of the tongue. 


\section{Case Reports in Oncology}

\begin{tabular}{l|l}
\hline Case Rep Oncol 2014;7:718-726 \\
\hline DOI: $10.1159 / 000368849$ & $\begin{array}{l}\text { C 2014 S. Karger AG, Basel } \\
\text { www.karger.com/cro }\end{array}$ \\
\hline
\end{tabular}

Sepúlveda et al.: Giant Undifferentiated Oropharyngeal Sarcoma: A Case Report and Review of the Literature

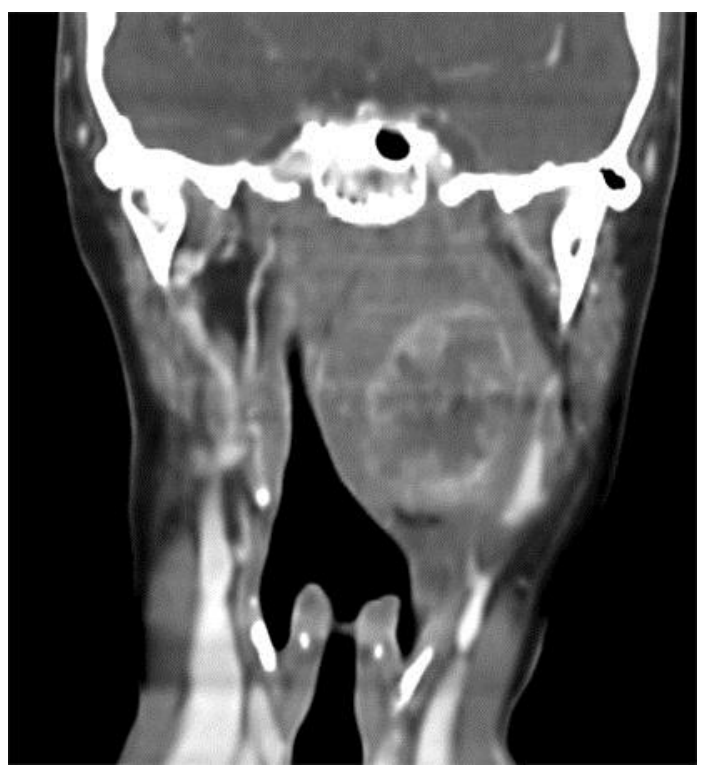

Fig. 3. Coronal CT after intravenous contrast injection: expansive cervical process showing that the medial border of the mass crosses the middle line.

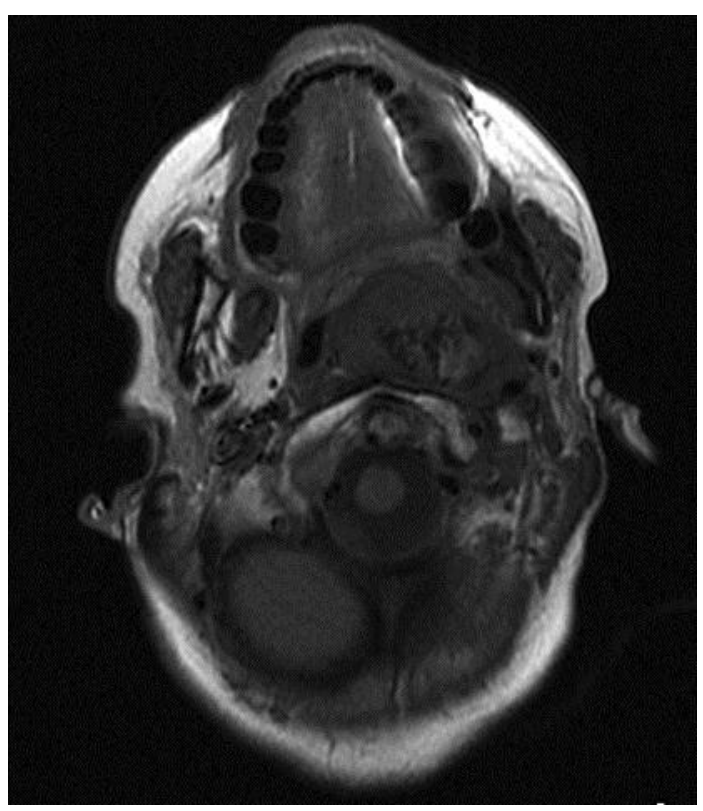

Fig. 4. MRI T1 sequence: a partially well-delimited iso- to hypointese expansive process. 


\section{Case Reports in Oncology}

\begin{tabular}{l|l}
\hline Case Rep Oncol 2014;7:718-726 \\
\hline DOI: $10.1159 / 000368849$ & $\begin{array}{l}\text { C 2014 S. Karger AG, Basel } \\
\text { www.karger.com/cro }\end{array}$ \\
\hline
\end{tabular}

Sepúlveda et al.: Giant Undifferentiated Oropharyngeal Sarcoma: A Case Report and Review of the Literature

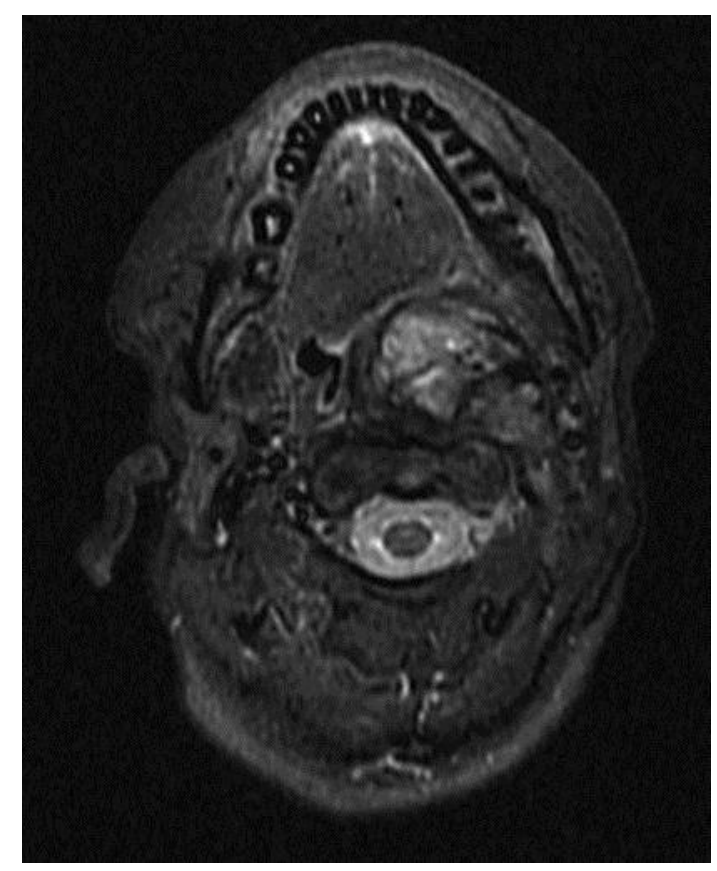

Fig. 5. MRI stir sequence: iso- to hyperintense mass decreasing the airway space.

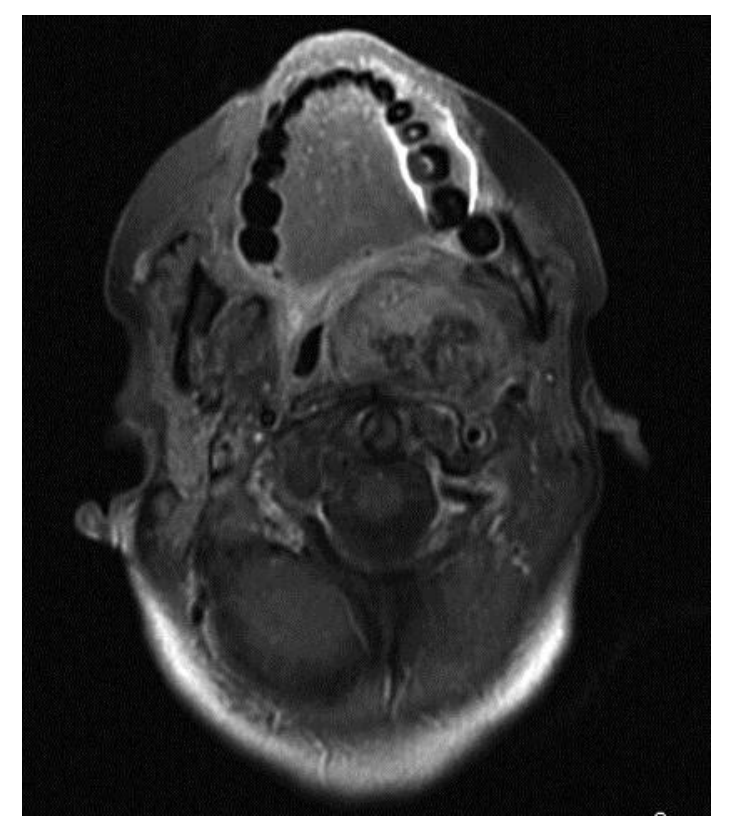

Fig. 6. MRI T1FSGD axial view: cervical mass with heterogeneous enhancement.

\section{KARGER}




\section{Case Reports in Oncology}

Case Rep Oncol 2014;7:718-726

DOI: 10.1159/000368849

Sepúlveda et al:: Giant Undifferentiated Oropharyngeal Sarcoma: A Case Report and Review of the Literature

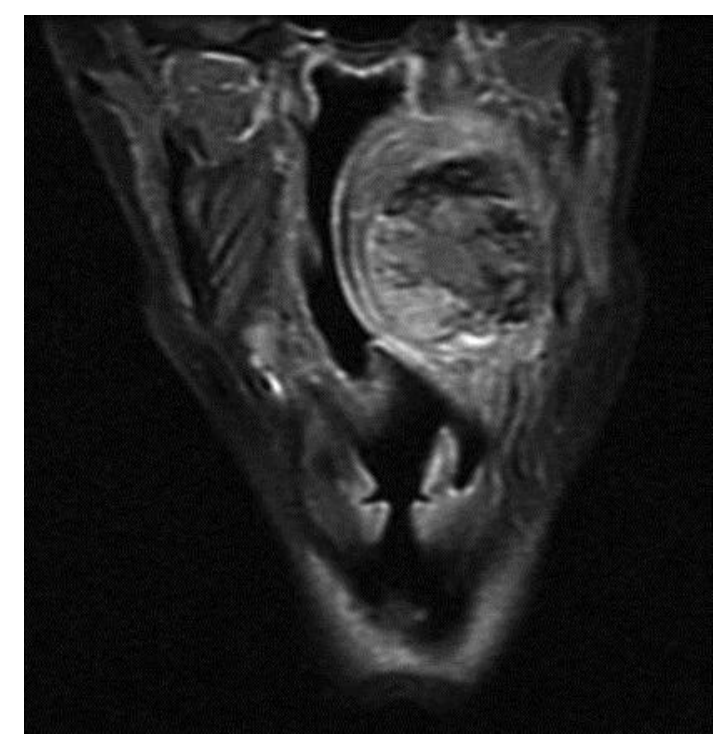

Fig. 7. MRI T1FSGD coronal view: the presence of some weak signals was suggestive of vascular structures within the mass.

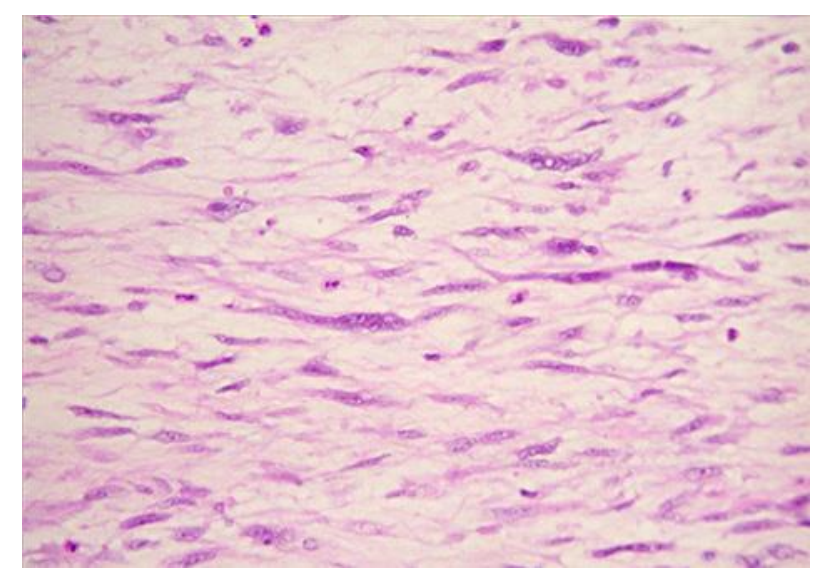

Fig. 8. HE stain. 


\section{Case Reports in Oncology}

\begin{tabular}{l|l}
\hline \multicolumn{2}{l}{ Case Rep Oncol 2014;7:718-726 } \\
\hline DOI: $10.1159 / 000368849$ & $\begin{array}{l}\text { ○ 2014 S. Karger AG, Basel } \\
\text { www.karger.com/cro }\end{array}$ \\
\hline
\end{tabular}

Sepúlveda et al:: Giant Undifferentiated Oropharyngeal Sarcoma: A Case Report and Review of the Literature

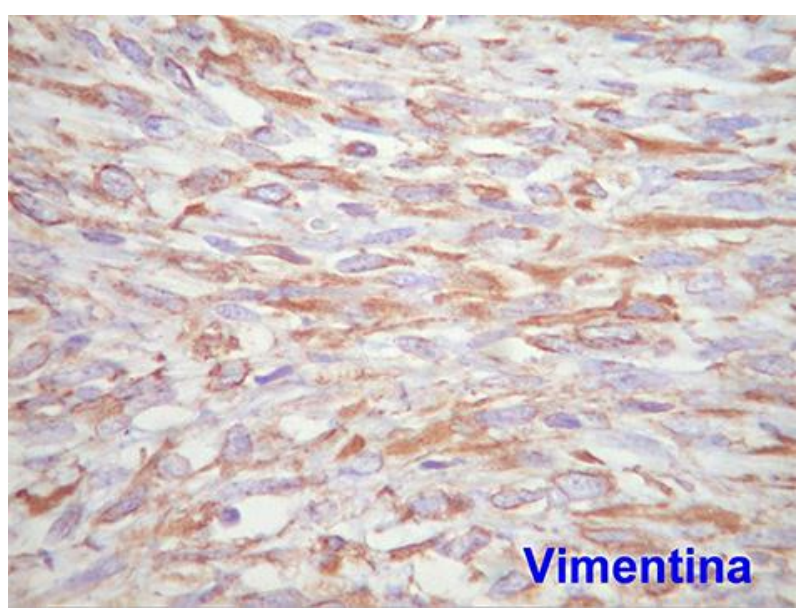

Fig. 9. Vimentin stain.

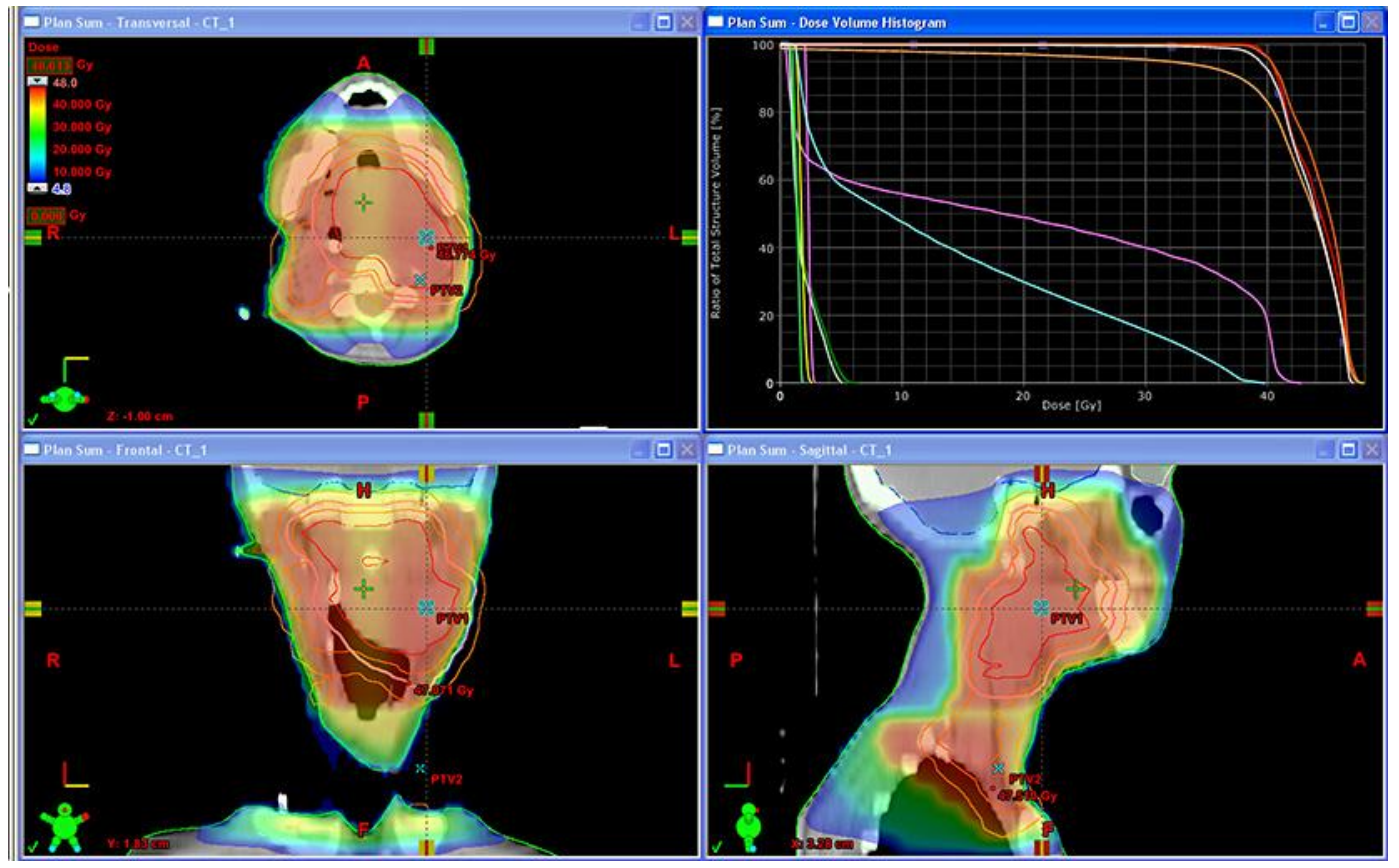

Fig. 10. 3-Dimensional radiotherapy plan. 